- RAM, REV. ADM. MACKENZIE, 16(6), Edição Especial • SÃO PAULO, SP • NOV.IDEZ. 2015 • ISSN 1518-6776 (impresso) • ISSN 1678-6971 (on-line) • http://dx.doi.org/10.1590/1678-69712015/administracao.v16n6p190-219. Submissão: 14 set. 2014. Aceitação: 25 jun. 2015. Sistema de avaliação: às cegas dupla (double blind review). UNIVERSIDADE PRESBITERIANA MACKENZIE. Silvio Popadiuk (Ed.), Silvio Popadiuk (Ed. Seção), p. 190-219.

\title{
PRÁTICAS COLABORATIVAS EM P\&D: UM ESTUDO NA INDÚSTRIA BRASILEIRA DE SEMICONDUTORES
}

\section{KADÍGIA FACCIN}

Mestra em Administração pelo Departamento de Ciências Sociais Aplicadas da Universidade de Caxias do Sul (UCS).

Professora do Departamento de Ciências Econômicas da Faculdade da Serra Gaúcha (FSG). Rua Os Dezoito do Forte, 2.366, Centro, Caxias do Sul - RS - Brasil - CEP 95020-472

E-mail: kadigia@gmail.com

\section{ALSONES BALESTRIN}

Doutor em Administração pela Universidade Federal do Rio Grande do Sul (UFRGS) e em Sciences de L'information et de La Communication pela Université de Poitiers. Professor do Programa de Pós-Graduação em Administração da Escola de Administração da Universidade do Vale do Rio dos Sinos (PPGA-Unisinos). Avenida Unisinos, 950, Cristo Rei, São Leopoldo - RS - Brasil - CEP 93022-000

E-mail: abalestrin@unisinos.br 


\section{RESUMO}

Recentes estudos apontam a necessidade de abertura do modelo de P\&D para uma maior interação, complementaridade e cooperação com atores externos. Assim, o ambiente da empresa passa a ser um ecossistema de relacionamentos orgânicos entre as diversas fontes de conhecimentos que interagem de forma dinâmica, criando o conhecimento aplicado no processo de P\&D. A questão que se coloca para a presente pesquisa é: "Quais são as práticas colaborativas de P\&D em uma indústria de alta complexidade tecnológica e como ocorrem?”. Para lançar luz à presente pesquisa, buscou-se investigar projetos colaborativos de P\&D na indústria brasileira de semicondutores. O presente artigo investiga a estrutura dos projetos colaborativos de P\&D na indústria de semicondutores conduzidos no Brasil, bem como desvenda as práticas colaborativas mais comuns entre os atores. Para o estudo de campo, foram investigados 2I projetos de $\mathrm{P} \& \mathrm{D}$, desenvolvidos por design houses brasileiras de 2008 a 2013. O estudo faz uma abordagem contextual dos projetos brasileiros, identificando quem são os principais atores, quais as suas contribuições mais relevantes e as formas de colaboração com seus parceiros. Os resultados demonstram uma série de práticas colaborativas nos projetos de P\&D. Na nascente indústria nacional de semicondutores, existe uma diversidade de interações entre fornecedores, clientes, universidades e agências de fomento, inclusive com concorrentes estrangeiros. De acordo com os resultados do estudo, parece possível enfatizar que, na indústria brasileira, há um conjunto amplo de laços não familiares e bastante fluidos, que se movem e configuram-se rapidamente. Cabe também ressaltar que o governo tem um papel importante na influência da inovação, baseando-se no princípio da interdependência, haja vista a criação de mecanismos dinâmicos e o fomento por parte de políticas públicas e ações governamentais, principalmente aquelas ações para incentivo da inovação e interação entre os atores, formação e capacitação de pessoas, exploração do comércio internacional, incentivo à captação de recursos, redução da carga tributária etc. Entre as principais práticas colaborativas empregadas, estão a colaboração em P\&D e aspectos gerenciais, a cocriação a montante e a jusante na cadeia produtiva, o financiamento de $P \& D$ e a aquisição de tecnologia. 


\section{PALAVRAS-CHAVE}

Práticas colaborativas. Projetos colaborativos. P\&D. Colaboração. Semicondutores.

\section{INTRODUÇÃO}

O modelo de pesquisa e desenvolvimento (P\&D) tem sido conduzido, conforme aponta a literatura, por processos mais fechados e de baixa interação com o ambiente externo. No entanto, com a crescente complexidade tecnológica que algumas indústrias de alta tecnologia vêm experimentando, esse modelo se torna limitado (Chesbrough, 2003; Chiarioni, Chiesa, \& Frattini, 2010; Han, Oh, Im, Hang, Oh e Pisnsommeault, 20I2). Recentes estudos, como os de Shin, Pisano e King (2008), Hughes e Wareham (2010) e Kapoor e McGrath (20I4), vêm apontando a necessidade de abertura do modelo de P\&D para uma maior interação, complementaridade e cooperação com atores externos por meio de uma série de práticas colaborativas. Isso se dá, principalmente, porque a ciência e a tecnologia evoluem a passos tão rápidos que até mesmo as grandes empresas já não têm como pesquisar a totalidade das áreas do conhecimento que contribuem para a melhoria e a inovação de seus produtos, já não podendo mais controlar todo o processo de produção.

Dessa forma, começam a surgir as primeiras constatações de que a inovação não é apenas um processo interno na firma, mas provém também de estratégias de cooperação para a criação de conhecimento com outros parceiros a partir de um processo de combinação de saberes e vivências diversas, bem como da formalização de projetos colaborativos de $\mathrm{P} \& \mathrm{D}$. Cabe destacar que as empresas intensivas em conhecimento, como a de semicondutores, atualmente desenvolvem a maior parte de suas inovações a partir do estabelecimento de projetos colaborativos, devido à necessidade de continuamente gerar inovações com alta velocidade (Brown \& Linden, 20II; Deng, 2008; Shih, Pisano, \& King, 2008).

Contudo, pouco se conhece sobre as práticas colaborativas adotadas por essas indústrias de alta complexidade (Zanzouri \& Francois, 20I3; Kapoor e McGrath, 20I4); assim, diante dessa carência, a questão que se coloca para a presente pesquisa é: "Quais são as práticas colaborativas de P\&D em uma indústria de alta complexidade tecnológica e como ocorrem?”. Para lançar luz à presente pesquisa, buscou-se investigar projetos colaborativos de P\&D na indústria brasileira de semicondutores. Para o estudo de campo, foram investigados 2i projetos de P\&D, desenvolvidos por design houses (DHs) brasileiras, desde o ano de 2008 até 2013.

O foco de análise deste estudo centra-se nas DHs, visto que elas são as empresas que se encontram no elo inicial da cadeia produtiva da indústria de 
semicondutores. As empresas de projeto, como também podem ser chamadas, destacam-se em termos de inovação, pois é, nessa etapa, que são definidas as funcionalidades dos chips. Sabe-se que essas funcionalidades definidas na etapa de projeto serão incorporadas aos produtos da indústria de eletrônica a jusante da indústria de semicondutores, de modo que a DH seja impulsionadora da inovação na cadeia produtiva.

O presente artigo tem, então, por objetivo investigar as práticas colaborativas de P\&D na indústria brasileira de semicondutores, bem como desvendar as principais contribuições apontadas no estabelecimento de práticas colaborativas por tipo de parceiro. O estudo faz uma abordagem contextual dos projetos brasileiros, identificando quem são os principais atores, quais as suas contribuições mais relevantes, assim como as práticas mais usuais de colaboração com seus parceiros.

Além deste texto introdutório, o artigo contém quatro seções. Na seção 2, é apresentado o referencial teórico que embasa a presente pesquisa. Na seção 3, destacam-se os aspectos metodológicos seguidos para a coleta de dados e análise dos resultados. Na seção 4, são mostrados os resultados da pesquisa, e, por fim, destacam-se as considerações finais do artigo.

\section{REFERENCIAL TEÓRICO}

\section{PROJETOS COLABORATIVOS DE P\&D}

Estudos recentes, sob a lente teórica das relações interorganizacionais, têm dedicado atenção ao estabelecimento de projetos colaborativos (Cropper, Ebers, $\&$ Huxham, 2008). Os projetos colaborativos envolvem o trabalho em conjunto para criar um produto ou serviço em um período limitado de tempo, representados por um conjunto de atividades que permite a múltiplas organizações alcançar objetivos individuais e coletivos (Jones \& Lichtenstein, 2008). Esses projetos, muitas vezes, envolvem múltiplos atores e organizações, com diferentes objetivos e níveis de conhecimento.

Durante a colaboração interorganizacional, podem estar envolvidos diversos atores ao longo do tempo. Para tanto, em um mesmo projeto, pode haver momentos em que as relações são diádicas e outras triádicas, evidenciando que, nem sempre, todos estão atuando ao mesmo momento. Há de se apontar também que a quantidade de atores envolvidos varia de acordo com a evolução do projeto. As díades se constituem na ligação direta entre dois atores, enquanto as tríades podem ser constituídas por uma ligação direta ou indireta entre três atores (Mizruchi, I993). Todavia, os estudos recentes, que se dedicam a esse tipo de investigação, não revelam essas características e esse processo de evolução. Na verdade, os 
estudos sobre projetos colaborativos ainda são uma "caixa-preta" para a corrente dos teóricos interorganizacionais (Calamel, Defélix, Picq, \& Retour, 20I2).

Para Aronson, Lechler, Reily e Shenhar (200I), a cooperação em projetos é definida como a fusão de duas ou mais partes, instituições ou indivíduos, que têm uma atribuição distinta, mas trabalham juntas. Um projeto interorganizacional apresenta atividades coordenadas apenas para a vida do projeto, o qual pode se estender por cinco dias ou 20 anos. Um projeto pode ser construído como uma sequência de eventos e depende de certa qualidade de temporalidade e das características da relação, como a frequência, a duração e a densidade da interação entre as organizações. A sequência, resultante dos eventos, é fortemente influenciada tanto pela estrutura das relações quanto pelas regras de colaboração mutuamente compartilhadas (Jones \& Lichtenstein, 2008).

O Quadro I traz algumas das principais definições de projetos colaborativos que embasam o entendimento deste trabalho.

QUADRO I

DEFINIÇÕES DE PROJETOS COLABORATIVOS

DEFINIÇÕES DE PROJETOS COLABORATIVOS

Projetos colaborativos envolvem múltiplas organizações que trabalham em conjunto, em uma atividade compartilhada, por um período de tempo limitado, em ambientes de incerteza e competitividade.

Entidades cooperam por um limitado período de tempo para alcançar objetivos específicos.

Organizações temporárias representam uma efetiva forma de integrar diferentes tipos de conhecimento e habilidade, e compartilhar riscos e incertezas relacionados a atividades complexas.

Fusão de duas ou mais partes, instituições ou indivíduos, que têm uma Aronson et al. atribuição distinta, mas trabalham juntos. AUTOR (2008)

Goodman e Goodman (1976) (2009)

Projeto é separado da atividade permanente da linha da organização. Uma mesma organização pode ter vários projetos em andamento ao mesmo tempo, alguns internamente e vários outros com diferentes

Jones e Lichtenstein

Rutten e Oerlemans atores em cada um.

Projetos colaborativos envolvem múltiplos atores e organizações com diferentes objetivos e níveis de conhecimento. São considerados caixas-pretas.

Calamel et al.

(2012)

Fonte: Elaborado pelos autores. 
Uma mesma organização pode ter vários projetos em andamento ao mesmo tempo: alguns internamente e vários outros com diferentes atores em cada um (Chesbrough, 2003). Isso significa que o projeto é, por conseguinte, separado da atividade permanente da linha da organização. Entretanto, é de extrema complexidade a integração de atividades de organizações diferentes (Axelsson \& Axelsson, 2006). A cooperação em projetos é exteriorizada em uma tentativa por parte das empresas de acessar recursos adicionais para além de suas fronteiras.

Os estudos recentes, que têm o projeto como objeto de análise, ainda são poucos (Dietrich, Eskerod, Dalcher, \& Sandhawalia, 2oıо; Ahola, 2009; Eloranta, 2007). A maior parte inclusive se dedica à descrição de benefícios pela participação das empresas em parcerias. Nesse conjunto de obras, também se encontram muitas delas que enfatizam a escolha de parceiros de acordo com as necessidades de complementaridade do projeto, ou seja, dedicam-se a explicar o motivo pelo qual a empresa decide colaborar com a universidade, o cliente ou o fornecedor (Cassiman, Di Guardo, \& Valentini, 2009), porém não destacam quais as práticas colaborativas mais usuais nesse tipo de acordo de colaboração.

Os tipos de projeto colaborativo podem variar de acordo com a duração curtos e longos -, com os tipos de laço - fracos ou fortes - e ainda com as atividades às quais se dedicam (Jones \& Lichtenstein, 2008). No que tange às atividades às quais se dedicam, também reconhecidas como colaborações tecnológicas, os projetos colaborativos de $\mathrm{P} \& \mathrm{D}$ representam a abertura do processo de P\&D em colaboração com atores externos, que são relações interorganizacionais focadas no desenvolvimento conjunto de inovações tecnológicas. Normalmente, entre os principais atores imbricados em processos de inovação, com os quais as empresas firmam acordos colaborativos, a literatura destaca os seguintes: fornecedores (Un, Cuervo-Cazurra, \& Asakawa, 2oıо; Pittaway, Robertson, Munir, Denyer e Neely, 20I4), instituições de ciência e tecnologia (Cohen \& Levinthal, I990; Furman \& McGarvie, 2009; Mowery, 20II), consumidores (Gassmann, Enkel, \& Chesbrough, 20I0; Pittaway et al., 20I4), concorrentes (Bengtsson \& Kock, I999; Bourreau \& Dogan, 20I0) e intermediários (Howells, 2006; Santamaría, Barge-Gil, \& Modrego, 20ıо; Johnson, 2008).

Apesar de os projetos colaborativos terem ganhado, na atualidade, um grande reconhecimento, ainda permanecem algumas questões não respondidas, vinculadas principalmente às abordagens de processo de colaboração em projetos colaborativos que possuem laços múltiplos, bem como a descrição das principais práticas colaborativas adotadas no desenvolvimento de um projeto. Utilizando as dimensões de análise das relações interorganizacionais propostas por Cropper et al. (2008), organizaram-se, no Quadro 2, os principais estudos avaliados sobre projetos colaborativos. Tal ilustração apresenta o que compreendem esses estudos - ou quais seus objetivos -, assim como alguns autores encontrados na revisão da literatura, a fim de demonstrar as abordagens mais deficientes. 


\section{QUADRO 2}

\section{PRINCIPAIS DIMENSÕES DE ANÁLISE}

DE PROJETOS COLABORATIVOS

\begin{tabular}{|c|c|c|}
\hline DIMENSÃO & O QUE COMPREENDEM OS ESTUDOS & EXEMPLOS DE ESTUDOS \\
\hline Organizacional & $\begin{array}{l}\text { Os estudos compreendem avaliações das } \\
\text { condições das empresas que se engajam } \\
\text { em projetos colaborativos e como essas } \\
\text { condições mudam após a sua participação. } \\
\text { Os estudos se detêm principalmente no } \\
\text { aumento dos lucros, no aumento do } \\
\text { número de patentes e na conquista de } \\
\text { vantagens competitivas. }\end{array}$ & $\begin{array}{l}\text { Hoang e Rothaermel (2010), } \\
\text { Kohtamäki, Partanen e Möller } \\
\text { (2013), Levitas e McFadyen } \\
\text { (2009), Barajas, Huergo e } \\
\text { Moreno (2012) e Thorgren, } \\
\text { Wincent e Örtqvist (2012) }\end{array}$ \\
\hline Contextual & $\begin{array}{l}\text { Condições que facilitam ou reprimem } \\
\text { as relações interorganizacionais. Além } \\
\text { disso, estão incluídos estudos que } \\
\text { avaliam o papel exercido pelo governo } \\
\text { no cofinanciamento de projetos e na } \\
\text { implementação de leis que motivam } \\
\text { parcerias interorganizacionais. }\end{array}$ & $\begin{array}{l}\text { Deck e Erkal (2013), } \\
\text { Mowery (2011) e } \\
\text { Marín e Siotis (2008) }\end{array}$ \\
\hline Relacional & $\begin{array}{l}\text { São estudados os fluxos de } \\
\text { informação, governança e estrutura do } \\
\text { relacionamento. }\end{array}$ & $\begin{array}{l}\text { Defélix, Colle e Rapiau (2008), } \\
\text { Morandi (2013), Tzabbar, } \\
\text { Aharonson e Amburgey } \\
\text { (2013), Gallego, Rubalcaba } \\
\text { e Suárez (2013), Brostrom } \\
\text { (2012), Hagedoorn e Wang } \\
\text { (2012) e Lindkvist (2005) }\end{array}$ \\
\hline Processual & $\begin{array}{l}\text { Evolução da relação e das ações } \\
\text { colaborativas ao longo do tempo. }\end{array}$ & $\begin{array}{l}\text { Davis e Eisenhardt (2011) } \\
\text { e Calamel et al. (2012) }\end{array}$ \\
\hline
\end{tabular}

Fonte: Elaborado pelos autores com base em Cropper et al. (2008).

De acordo com a avaliação do quadro elaborado, fica claro que existem ainda poucos estudos que se dedicaram à análise do processo de colaboração em projetos colaborativos, o que enfatiza a afirmação de que o que acontece dentro dos projetos, como unidades de análise, ainda é uma "caixa-preta" e merece uma atenção especial. Por esse motivo, é que este estudo se dedica às ações e práticas colaborativas em projetos de P\&D. 


\subsection{PRÁTICAS COLABORATIVAS EM PROJETOS CONJUNTOS DE P\&D}

Muitos dos estudos sobre colaborações tecnológicas foram enriquecidos por conceitos advindos da biologia evolucionista e da psicologia cognitiva, incorporando dimensões que deram origem a novos conceitos de interatividade e troca. No entanto, é efetivamente desde a década de i980 que as pesquisas começaram a fazer frente às demandas sobre a geração de novos conhecimentos e a potencialização dos gastos com $\mathrm{P} \& \mathrm{D}$, trazendo os conceitos de interatividade para os estudos.

Nesse ínterim, surgem estudos como os de Kline e Rosenberg (I986) que já consideravam, na análise do processo de inovação, a importância dos recursos auferidos por meio do processo interativo. Especialmente a partir de uma perspectiva evolutiva da inovação (Nelson \& Winter, I982), a heterogeneidade ou a variedade de parceiros e informações se destacam como fontes importantes de inovação.

De acordo com Rothwell (I995), a inovação é significativamente e cada vez mais influenciada pela formação de redes de colaboração e alianças, levando a uma variedade de relacionamentos externos. Isso decorre do aumento das alianças estratégicas, do $P \& D$ colaborativo, da maior consciência para a gestão da cadeia de suprimento, do crescimento de redes entre pequenas e médias empresas com empresas grandes e do crescimento das redes entre pequenas empresas.

Alguns conceitos da biologia evolucionista, a exemplo do conceito de ecossistema, enfatizam que, para que a organização se mantenha inovadora, precisa estar em interação e troca em fluxo contínuo com o ambiente em que ela está inserida. Isso é mais do que ter apenas um processo de inovação aberta; trata-se, na verdade, de um processo de inovação colaborativa que envolve a criação de conhecimento a partir de um processo dialético e de sintetização dos mais diversos conhecimentos entre os membros de um projeto, visando à criação de um conhecimento novo e coletivo que se concretiza por meio das práticas colaborativas.

Expresso de outro modo, vivencia-se a mudança da gestão de P\&D linear para o processo de gestão do fluxo de conhecimento de forma sistêmica. Dessa maneira, quando o projeto de P\&D passa a ser conduzido de forma colaborativa, a visão do processo de inovação passa a ser holística e supera o estabelecimento linear e cartesiano em P\&D encontrado em muitos trabalhos na área de estudos de inovação.

É possível dizer que uma grande quantidade dos estudos faz algum tipo de referência à troca, complementaridade ou criação de conhecimento em acordos 
de colaboração (Gallego et al., 20I3; Brostrom, 20I2; Hagedoorn \& Wang, 20I2; Lindkvist, 2005). Todavia, a maior parte desses estudos negligencia o processo colaborativo que cria o conhecimento novo, não apresentando ou destacando quais práticas enriquecem o resultado dos projetos colaborativos de P\&D.

Existem também alguns estudos que se dedicam a entender a natureza dos laços, as características das equipes ou as condições que facilitam a evolução e o sucesso do projeto (Dietrich et al., 2010; Davis \& Eisenhardt, 20II).

O estudo de Davis e Eisenhardt (20II) refere a necessidade de relações simbióticas em projetos de colaboração tecnológica. Os autores partem do questionamento sobre o porquê alguns projetos produzem inovação tecnológica e outros não. Após a condução do estudo, Davis e Eisenhardt (20II) concluem que apenas os projetos que conseguem estabelecer relações simbióticas sobrevivem. Embora a contribuição dos autores seja bastante importante para os avanços dos entendimentos dos teóricos de relações interorganizacionais, ainda assim eles não destacam quais práticas de colaboração estão vinculadas às relações simbióticas.

Também Defélix et al. (2008) enfatizam a necessidade de condução dos projetos para a obtenção do seu sucesso, destacando o estudo do processo de inovação. Já Calamel et al. (20I2) ressaltam a necessidade de coordenação entre atores múltiplos em projetos de inovação, chamando esse processo de "construção da colaboração"; contudo, nenhum deles aponta como se constrói a colaboração do ponto de vista das ações firmadas entre os atores.

O sucesso de um projeto colaborativo de P\&D envolve a combinação e criação de conhecimento, a combinação de tecnologias e de outros recursos por meio das fronteiras organizacionais (Davis \& Eisenhardt, 20II). Desse modo, as empresas se engajam na aquisição de conhecimentos e tecnologias específicas por meio de uma ampla diversidade de arranjos colaborativos (Roijakkers \& Hagedoorn, 2006). Para Malerba (2002), cada um dos atores de um sistema possui competências específicas de processamento e armazenamento de conhecimento em seu contexto institucional. Para o autor, diferentes agentes sabem fazer distintas atividades de maneiras parecidas.

Dessa forma, o aprendizado, o conhecimento e o comportamento são entendidos como enraizados na heterogeneidade desses atores por experiência, competência, organização e desempenho diferenciados, assim como são caracterizados por processos específicos de aprendizagem, competências, estruturas e comportamentos (Breschi \& Malerba, I997). Nesse sentido, reconhecer as práticas que fomentam o sucesso de projetos colaborativos se torna uma importante contribuição teórica para o contínuo desenvolvimento do entendimento das relações interorganizacionais.

Na próxima seção, apresenta-se o método que embasou a coleta de dados e a análise dos resultados desta pesquisa. 


\section{METODOLOGIA}

O presente estudo é um estudo de caso (Yin, I994), que é uma metodologia aplicada para avaliar ou descrever situações dinâmicas em que o elemento humano está presente: "Busca-se apreender a totalidade de uma situação e, criativamente, descrever, compreender e interpretar a complexidade de um caso concreto, mediante um mergulho profundo e exaustivo em um objeto delimitado" (Martin, 2008, p. II). Na abordagem de Yin (I994, p. 2I), o estudo de caso como ferramenta de investigação cientifica "é utilizado para compreender processos na complexidade social nas quais estes se manifestam: seja em situações problemáticas, para análise dos obstáculos, seja em situações bem-sucedidas, para avaliação de modelos exemplares".

O caso a ser estudado nesta pesquisa é a indústria brasileira de semicondutores. Essa estratégia de pesquisa é indicada para estágios iniciais e etapas exploratórias de um dado fenômeno (Meredith, I998; Yin, I994). Além disso, o estudo de caso pode fornecer uma descrição rica do fenômeno estudado (Siggelkow, 2007).

A indústria de semicondutores se destaca no cenário internacional como um dos segmentos mais dinâmicos do setor de tecnologias. Desde I950, a indústria de semicondutores tem mostrado uma taxa de crescimento impressionante. Essa indústria representa cifras anuais de aproximadamente 250 bilhões de dólares em todo o mundo (Semiconductor Industry Association, 20I0). No entanto, o Brasil é um dos poucos países, entre as maiores economias mundiais, a não possuir um complexo eletrônico que contemple a manufatura de circuitos integrados (Gutierrez \& Leal, 2004). Apesar de estar entre os cinco maiores mercados mundiais de computadores pessoais, produzindo mais de $70 \%$ do que consome, o Brasil ainda depende da importação de semicondutores e displays para abastecer suas linhas de produção.

Vale destacar que os semicondutores representam uma parcela crescente do custo de muitos produtos. A não participação na produção da propriedade intelectual ou produção de partes desses componentes microeletrônicos terá um peso muito negativo sobre a indústria brasileira, bem como sobre a balança comercial do país em décadas futuras. Portanto, não há dúvida a respeito da importância de o país ter capacitação em projeto de circuitos integrados e participar de parte do ecossistema de microeletrônica (Ministério da Ciência, Tecnologia e Inovação [MCTI], 20II).

Diante desse contexto, o setor encontra sustentação à medida que amplia a capacidade do país em competir na economia do conhecimento (Agência Brasileira de Desenvolvimento Industrial [Abdi], 20II). Segundo a Abdi (20II), a 
consolidação de uma indústria de componentes semicondutores no país é fundamental para a competitividade, uma vez que ela gera as condições necessárias ao domínio da tecnologia, com ampliação da inovação e geração da riqueza. Assim sendo, o governo nacional colocou em prática o programa Circuito Integrado Brasil (CI Brasil), dando vida a uma estratégia de desenvolvimento e recriação da indústria de semicondutores nacional, com foco na etapa de projeto, operacionalizada por empresas chamadas DHs.

Primeiramente, buscou-se a identificação da existência de projetos colaborativos na indústria de semicondutores com foco nas práticas colaborativas utilizadas pelas DHs, visando ao desenvolvimento de seus projetos a partir dos dados encontrados no site do programa CI Brasil. O CI Brasil é um programa da Secretaria de Política de Informática (Sepin) do MCTI que nasceu de uma ação conjunta entre o governo federal, empresas e o setor acadêmico, uma estratégia baseada em relações interorganizacionais. O programa tem como objetivos, além de incentivar a atividade econômica na área de projetos de CI, expandir a formação de projetistas de circuitos integrados e promover a criação de uma indústria nacional de semicondutores (Abdi, 20II). Nessa busca, foram identificadas 2I empresas de projeto de semicondutores (DHs) existentes no Brasil, as quais são listadas no Quadro 3.

\section{QUADRO 3}

DESIGN HOUSES BRASILEIRAS

\begin{tabular}{llll}
\hline & DH & SITE & LOCALIZAÇÃO \\
\hline 1 & Eldorado & http://www9.eldorado.org.br/ & Campinas - SP \\
\hline 2 & Cesar & www.cesar.org.br & Recife - PE \\
\hline 3 & CTI-Renato Archer & www.cti.gov.br/design-house-home & Campinas - SP \\
\hline 4 & Ceitec S/A & www.ceitec-sa.com & Porto Alegre - RS \\
\hline 5 & Freescale & www.freescale.com & Campinas - SP \\
\hline 6 & CT-PIM & www.ctpim.org.br & Manaus - AM \\
\hline 7 & Cetene & www.cetene.gov.br & Recife - PE \\
\hline 8 & Excelchip & www.excelchip.com & São Paulo - SP \\
\hline 9 & Chipus & www.chipus-ip.com & Florianópolis - SC \\
\hline
\end{tabular}

(continua) 


\section{QUADRO 3 (CONCLUSÃO)}

DESIGN HOUSES BRASILEIRAS

\begin{tabular}{llll}
\hline & DH & SITE & LOCALIZAÇÃO \\
\hline 10 & DHBH & www.dhbh.org.br & Belo Horizonte - MG \\
\hline 11 & LSI-TEC & www.lsitec.org.br & São Paulo - SP \\
\hline 12 & DF-Chip & www.dfchip.com & Brasília - DF \\
\hline 13 & Floripa DH & www.floripadh.com & Florianópolis - SC \\
\hline 14 & Minasic & www.minasic.com & Itajubá - MG \\
\hline 15 & Wernher Von Braun & www.vonbraunlabs.org & Campinas - SP \\
\hline 16 & TE@I2 & www2.ee.ufpe.br/dhtei2 & Recife - PE \\
\hline 17 & SMDH & w3.ufsm.br/smdh/ & Santa Maria - RS \\
\hline 18 & Idea & www.idea-ip.com & Campinas - SP \\
\hline 19 & SiliconReef & www.siliconreef.com.br & Recife - PE \\
\hline 20 & Perceptia & www.perceptia.com & Campinas - SP \\
\hline 21 & NPCl & - & Rio de Janeiro - RJ \\
\hline
\end{tabular}

Fonte: Elaborado pelos autores com base nos dados disponíveis CI Brasil (20II).

Para a coleta de dados, utilizou-se um questionário elaborado pelos autores, que foi encaminhado por e-mail para as DHs. Os objetivos desse questionário foram os seguintes: investigar a estrutura dos projetos colaborativos firmados e as práticas de colaboração entre os atores, e destacar as principais contribuições evidenciadas por cada tipo de ator durante a prática colaborativa da criação de conhecimento que leva à inovação, demonstrando a sistemática de trabalho adotada pelos agentes sob a lente da dialética empresarial. O questionário aplicado às empresas foi dividido em grupos de questões conforme os focos de análise, de acordo com o que se apresenta no Quadro 4. 


\section{QUADRO}

\section{ELABORAÇÃO DO QUESTIONÁRIO DE ACORDO COM FOCOS DE ANÁLISE}

\begin{tabular}{|c|c|c|}
\hline FOCO DE ANÁLISE & INTERESSES DE PESQUISA & BASE TEÓRICA \\
\hline $\begin{array}{l}\text { Projetos } \\
\text { conjuntos de } \\
\text { P\&D }\end{array}$ & $\begin{array}{l}\text { - Total de projetos } \\
\text { desenvolvidos } \\
\text { - Fatores imprescindíveis à } \\
\text { colaboração em projetos } \\
\text { colaborativos de P\&D }\end{array}$ & $\begin{array}{l}\text { Dittrich e Duysters (2007), Noteboom } \\
\text { (2008), Dyer e Singh (1998), Balestrin e } \\
\text { Verschoore (2008), Aronson et al. (2001), } \\
\text { Granovetter (1973), Axelrod (2010) e } \\
\text { Nonaka, Toyama e Hirata (2011) }\end{array}$ \\
\hline $\begin{array}{l}\text { Práticas } \\
\text { colaborativas }\end{array}$ & $\begin{array}{l}\text { - Atores } \\
\text { - Formas de colaboração }\end{array}$ & $\begin{array}{l}\text { Nonaka et al. (2011), Prahalad e } \\
\text { Ramaswamy (2000), Un et al. (2010), } \\
\text { Cohen e Levinthal (1990), Gassmann } \\
\text { et al. (2010), Pittaway et al.(2014), } \\
\text { Bengtsson e Kock (1999), Howells (2006) } \\
\text { e Chesbrough (2003) }\end{array}$ \\
\hline $\begin{array}{l}\text { Principais } \\
\text { contribuições } \\
\text { por ator }\end{array}$ & $\begin{array}{l}\text { - Contribuições/benefícios da } \\
\text { colaboração - por ator }\end{array}$ & $\begin{array}{l}\text { Kapoor e McGrath (2014), Davis e } \\
\text { Eisenhardt (2011), Pittaway et al. (2014), } \\
\text { Bengtsson e Kock (1999) e Howells (2006) }\end{array}$ \\
\hline
\end{tabular}

Fonte: Elaborado pelos autores.

A construção de um questionário, segundo Aaker, Kumar e Day (200I), é considerada uma "arte imperfeita", pois não há procedimentos exatos que garantam que seus objetivos de medição sejam alcançados com boa qualidade. Assim, visando diminuir imperfeições, o questionário foi discutido com um engenheiro de uma DH; a partir dessa conversa, realizaram-se importantes considerações antes da distribuição.

O site de cada uma das DHs foi acessado para identificação dos contatos telefônicos e e-mails de responsáveis por projetos. Nas DHs, onde essas informações não estavam disponíveis, foi realizada ligação telefônica para coleta dos e-mails dos responsáveis. Uma vez identificados os contatos, encaminharam-se três e-mails em diferentes datas, e seis empresas não retornaram os questionários com as respostas. Ao final, a pesquisa obteve informações sobre a estrutura de 2I projetos colaborativos desenvolvidos pelas DHs brasileiras.

As pesquisas de natureza tipicamente qualitativa - como esta - geram um enorme volume de dados que precisam ser organizados e compreendidos (Teixeira, 2003, p. 192): "Esse processo é complexo, não-linear e implica um trabalho de redução, organização e interpretação dos dados”. A maioria das técnicas de análise procura seguir os padrões da análise quantitativa, ou seja, tem o propósito 
de contar a frequência de um fenômeno e procurar identificar relações entre os fenômenos, com a interpretação dos dados recorrendo a modelos conceituais definidos a priori. A Figura I auxilia na ilustração do modelo teórico-empírico que norteia a metodologia e análise empregadas neste estudo, a fim de atingir o objetivo proposto.

\section{FIGURA I}

\section{FRAMEWORK PARA CONDUÇÃO DA PESQUISA}

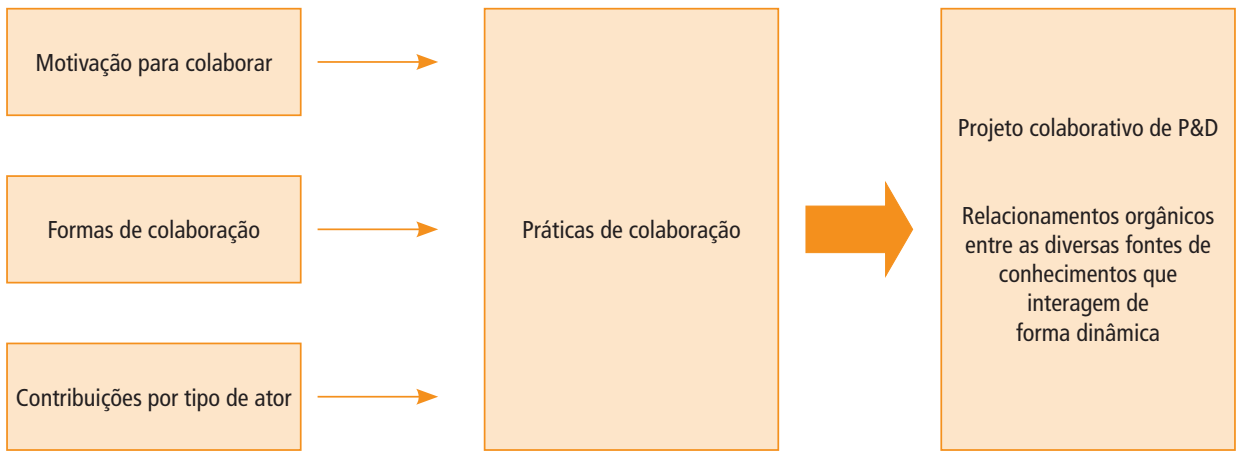

Fonte: Elaborada pelos autores.

O conjunto dessas técnicas é conhecido como "análise de conteúdo", que, segundo Minayo (I994), é a expressão mais comumente usada para representar o tratamento dos dados de uma pesquisa qualitativa. Na próxima seção, serão destacados os principais resultados auferidos na presente pesquisa a partir da análise de conteúdo dos dados coletados.

\section{APRESENTAÇÃO DOS RESULtAdOS \\ 4.1 A INDÚSTRIA DE SEMICONDUTORES BRASILEIRA E A IMPORTÂNCIA DA DH}

A indústria de semicondutores se destaca no cenário internacional como um dos segmentos mais dinâmicos do setor de tecnologias. O uso de semicondutores possibilita múltiplas aplicações no meio ambiente, no esporte, na segurança, na automação, no transporte e na saúde, gerando impacto de dimensões culturais e econômicas; além de contribuir para a geração de emprego para recursos humanos com alta qualificação (Chandler, 2002). 
Tendo em vista a importância dos semicondutores para a indústria nacional, no início dos anos 2000 , era latente a preocupação governamental com o desenvolvimento tecnológico do país. Para entender qual indústria seria foco de incentivos prioritários, foram realizados diversos debates e encontros com representantes de várias indústrias. Após a análise das possibilidades, percebeu-se que uma atividade capaz de contribuir para o desenvolvimento nacional seria a indústria de semicondutores.

Essa indústria já havia sido alvo de fomento no início da década de I960, porém, após a abertura do mercado na década de I990, ela sofreu com a livre concorrência e praticamente foi exterminada no país (Bortolaso, Teixeira, Balestrin, \& Faccin, 20I3). Dessa forma, diversos atores e ações foram mobilizados para que se constituísse novamente no Brasil uma indústria de semicondutores competitiva em níveis globais. O Brasil optou pelo desenvolvimento das empresas chamadas DHs.

Os fabricantes de circuitos integrados são classificados de acordo com o tipo de negócio ou a forma de atuação na cadeia de valor. Assim, eles podem ser classificados como: fabricantes integrados, empresas sem fábrica, fundições especializadas, empresas encapsuladoras, empresas de projeto independente e empresas de propriedade intelectual.

As empresas enquadradas como fabricantes integrados realizam todo o processo de produção do semicondutor, da concepção do componente até a entrega ao consumidor do produto. Já as empresas denominadas sem fábricas são responsáveis pelo projeto do produto e as detentoras da marca e do mercado perante os clientes. As empresas conhecidas como fundições especializadas realizam unicamente o processamento físico-químico dos produtos. As encapsuladoras são dedicadas à etapa de back-end. As empresas conhecidas como empresas de projeto independente (DHs) realizam o desenho do circuito. E, por fim, as empresas de propriedade intelectual desenvolvem células específicas de projeto e as licenciam a terceiros, sendo remuneradas por meio de pagamento de royalties.

A DH é o tipo de empresa responsável pelo projeto do circuito integrado. A etapa de projeto dispara os avanços nas etapas de front-end e back-end, na medida em que

[...] determina as condições geométricas necessárias para permitir a concepção e o projeto das novas funcionalidades dos chips da nova geração. Dessa forma, atua como driver do processo de miniaturização das estruturas semicondutoras e nos avanços tecnológicos das foundries (Abdi, 20II, p. 26). 
Assim sendo, a necessidade de agregação de novas funcionalidades, redução de consumo etc. nos novos chips, iniciada pela etapa de projeto, transborda para a etapa de front-end e estimula o desenvolvimento da indústria de fotogravação e revelação, da indústria química, da indústria de filtração especial e da indústria de máquinas e equipamentos, que é fornecedora da indústria de semicondutores. Um novo ciclo evolucionário - novo nó tecnológico - da indústria de semicondutores dispara um ciclo evolutivo em diversas outras indústrias correlatas (Abdi, 20II).

A etapa de projeto ou o trabalho da DH destaca-se em termos de inovação, pois é nessa etapa que são definidas as funcionalidades dos chips. Sabe-se que essas funcionalidades serão incorporadas aos produtos da indústria de eletrônica a jusante da indústria de semicondutores. As indústrias de telecomunicações, computação, automobilística, bens de capital, equipamentos médicos, automação, entre outras, oferecerão ao mercado produtos finais com as funcionalidades determinadas no projeto dos chips. Essa correlação adquire grande relevância no sucesso ou fracasso dos produtos finais. As funções oferecidas pelos produtos finais foram estabelecidas durante o processo de projeto do chip que, em alguns casos, são acrescidas de soluções de software embarcado, também previstas no projeto. O sucesso do chip determina o sucesso do produto final. O domínio tecnológico do chip provoca o domínio tecnológico do produto final.

Devido às características destacadas, trata-se da etapa que mais demanda criatividade, mais sela acordos de colaboração e se utiliza de práticas colaborativas para incentivar a complementaridade de recursos.

\subsection{CARACTERIZAÇÃO DOS PROJETOS DE P\&D}

A partir dos resultados fornecidos pelas DHs, com relação aos projetos desenvolvidos conjuntamente e às práticas de colaboração adotadas, pode-se destacar que, dentre os principais fatores apontados como imprescindíveis para a manutenção de um acordo de colaboração do tipo temporário, em que existem o diálogo e, portanto, a troca de conhecimentos e a criação de outros novos, as DHs apontaram a necessidade de que as empresas estejam com suas prioridades alinhadas; isso inclui tempo e equipe disponíveis para se engajar no projeto colaborativo, ou seja, uma espécie de sincronia nas demandas.

As empresas destacam ainda que o sucesso de um projeto colaborativo passa pela definição de acordos formais. A definição de metas por meio de acordos formais é um importante fator para evitar disputas com propriedade intelectual. Todas as empresas informaram que possuem acordos formais para os seus projetos, contrariando uma vasta literatura que afirma que os contratos podem 
ser predatórios no processo de inovação. Isso ocorre porque a necessidade de inovação aumenta a incerteza de contingências, tornando difícil especificar a governança formal, especialmente por contrato, o que aumenta a necessidade de colaboração com base na confiança (Noteboom, 2008). Contudo, pode-se destacar que as empresas brasileiras ainda se dedicam a projetos de menor complexidade, o que parece justificar a possibilidade de formalizar a maior parte dos contratos vigentes.

Algumas delas enfatizaram que a proximidade cultural das empresas - seja física ou virtual -, assim como a existência de relação de amizade entre os profissionais das DHs, facilita as trocas entre elas. Um fator recorrente nos apontamentos das empresas revela que ter uma capacidade diferente (complementar) é muito importante e, por vezes, determinante na escolha do parceiro, uma vez que essa diferença agrega valor ao produto. Dito de outro modo, as empresas parecem procurar parceiros que tenham uma cultura semelhante, mas com conhecimentos diferentes.

O estudo de Paier e Scherngell (20II) destaca que a escolha dos parceiros depende das características específicas da empresa - tamanho, estrutura, indústria, organização, tipo, estratégia e alvo -, bem como do foco dos esforços de P\&D - produto ou processo de inovação, pesquisa básica ou aplicada, desenvolvimento tecnológico - sobre as características relacionais entre parceiros de colaboração, assim como também dos custos envolvidos na cooperação com outros.

Okamuro (20II) vai mais adiante acerca da questão do relacionamento estrutural entre as empresas e aponta que as características específicas dos fundadores, como a formação educacional, os resultados da colaboração anterior e a filiação a associações acadêmicas, são bastante importantes para determinar o sucesso da cooperação de $\mathrm{P} \& \mathrm{D}$ com instituições acadêmicas - universidades e institutos de pesquisa.

O uso de ferramentas de tecnologia da informação, como internet, sistemas de informação empresariais, bancos de dados, repositórios de documentos, Skype e-mail, parece ser indispensável para compensar distâncias entre parceiros, conforme dados da presente pesquisa. Há um crescente consenso de que as firmas que possuem uma estratégia do tipo exploration, para o desenvolvimento de novos produtos, estabelecem alianças caracterizadas por laços fracos (Granovetter, I973). Nesse contexto, os laços fracos contexto indicam pequeno comprometimento e parceiros não familiares, pois o foco é aprender e criar novas ideias vindas de novos parceiros (Dittrich \& Duyster, 2007). Deve haver uma distância cognitiva tecnológica entre os parceiros, para que eles possam oferecer algo novo uns aos outros (Noteboom, 2008). A vantagem está na combinação de diferentes formas de conhecimento. Os laços diversos e mais fracos entre as empresas, universidades e instituições de pesquisa, nessas redes, dão aos membros acesso 
a maior diversidade de informações. Essa informação diversificada pode, então, ser recombinada para criar um novo conhecimento que vai além do existente (Ahmadjian, 2008).

Vinculados também às interações com parceiros não familiares - aquelas em que as relações são constituídas por laços fracos -, os fatores mais importantes para o sucesso do trabalho colaborativo são a identificação entre as equipes de trabalho, a tolerância, o respeito, a acessibilidade, o diálogo aberto e a autonomia, que são essenciais aos profissionais que colaboram temporariamente. $\mathrm{Na}$ discussão sobre a promoção da cooperação, Axelrod (2010, p. I26) destaca que as "pessoas precisam se importar umas com as outras". Axelrod (20I0) destaca que o altruísmo se constitui então em um bom motivo para a ação. O motivo pode ser mais para criar uma obrigação a melhorar o bem-estar do beneficiário, fazendo com que a pessoa retorne a reciprocidade como a base da cooperação (Axelrod, 20I0).

Além dos 2I projetos já desenvolvidos pelas DHs brasileiras e que são foco do presente estudo, acrescenta-se que atualmente estão em desenvolvimento outros 22 projetos de aplicação em novos produtos. Desses 22 projetos, oito estão sendo desenvolvidos em colaboração com algum ator da cadeia produtiva ou interface institucional. Parece, então, possível afirmar que aproximadamente $40 \%$ do que está sendo produzido por essa indústria será fruto da colaboração entre as empresas.

Observa-se que as DHs perceberam os ganhos da utilização de estratégias coletivas. De acordo com a visão relacional, a estratégia coletiva cria uma fonte inimitável de recursos por meio de uma rede com acesso valioso a informações, compartilhamento de conhecimento, complementaridade de recursos e governança efetiva. Na maior parte dos trabalhos, a visão relacional da estratégia tem tido como preocupação empírica a busca do entendimento dos ganhos relacionais percebidos pela atuação conjunta de empresas em diversos tipos de indústria (Dyer \& Singh, I998).

\section{3 PRÁTICAS COLABORATIVAS E PRINCIPAIS CONTRIBUIÇÕES}

Uma das questões elencadas no questionário distribuído às DHs demandava a identificação das principais contribuições dos atores no processo de colaboração. Entre as principais respostas, destacaram-se: a complementaridade de recursos, o treinamento da equipe, o apoio logístico - importação, despachantes aduaneiros, negociação de contratos com fornecedores -, os recursos financeiros para aquisição de equipamentos e software de projetos, a transferência de know-how tecnológico, a transferência de processos e metodologias - treinamento prático 
on-the-job durante o projeto conjunto -, a transferência de templates de processos e ferramentas de controle, o acesso a diversas normas que têm alto custo de aquisição, o aprendizado de metodologias avançadas de levantamento de traceabilidade de requisitos ao longo do projeto até o produto final, a aculturação em planejamento e condução de projeto - voltado para a precisão nas estimativas e para o cumprimento dos prazos, para a elevada qualidade da documentação e dos entregáveis de projeto em todas as etapas -, o aumento dos potenciais clientes para produtos, a constante troca de informações sobre o mercado e as políticas do setor e de referências profissionais. Alguns parceiros oferecem infraestrutura e apoio administrativo, gerencial, jurídico e de marketing, deixando os empreendedores livres para focar no core-business. E todo esse conjunto de contribuições possibilita a projeção de chips inovadores.

A análise de conteúdo apontou que as três principais formas de colaboração utilizadas pelas DHs são: a parceria, em que duas ou mais empresas dividem os estágios do fluxo entre elas - cada uma fica com sua especialidade e as duas se complementam -, normalmente firmada com outra DH que possui capacidade complementar; a consultoria, em que uma empresa contratada oferece o know-how necessário para realizar as etapas que a empresa contratante não tem condições de fazer sozinha, que é quando acontece a cocriação com um fornecedor da DH - etapas de back-end; e a cocriação com um cliente.

Com base nas considerações evidenciadas, elaborou-se o Quadro 5, que permite fazer algumas considerações sobre as práticas colaborativas das DHs no contexto da indústria brasileira de semicondutores. Assim, esse quadro possibilita inferir que as diferenças entre os objetivos compartilhados em cada projeto e a forma como os vínculos estão organizados geram, em cada caso, uma externalidade idiossincrática, que depende essencialmente da combinação dos elementos existentes, ou seja, nem todos os atores oferecem as mesmas contribuições em todos os projetos de colaboração, basta observar as DHs concorrentes e os fornecedores, por exemplo, que apresentam, neste estudo, uma amplitude maior de contribuições, de acordo com a forma de colaboração para a qual se apresenta como parceira.

Dittrich e Duysters (2007) apontam, no estudo sobre as redes de inovação da Nokia, que há "diferentes propostas em diferentes períodos", assim como está evidenciado aqui que o gerenciamento do processo exige a capacidade de promover e administrar essas interações, de acordo com cada objetivo e situação empresarial, refletindo em diferentes modelos para o trabalho colaborativo e a criação do conhecimento interorganizacional.

Em seu estudo sobre criação de conhecimento interorganizacional, Ahmadjian (2008) destaca a não existência de um modelo padrão para a criação de conhecimento. $\mathrm{O}$ autor complementa sua análise enfatizando que o modelo certo 
de criação do conhecimento interorganizacional depende da natureza do conhecimento e varia de acordo com a indústria, o ambiente e a tecnologia. Assim, enquanto o modelo da Toyota é mais efetivo na transformação do conhecimento tácito em conhecimento explícito, o modelo do Vale do Silício é mais efetivo na seleção e na recombinação do conhecimento a partir de uma ampla variedade de fontes - e na criação do conhecimento completamente novo ou no encontro de novos usos para os existentes (Ahmadjian, 2008). Tomando as premissas desse estudo para analisar a estrutura da indústria brasileira de semicondutores, parece possível evidenciar que o modelo adotado pela indústria brasileira de semicondutores conta com uma ampla variedade de fontes de conhecimento e uma ampla quantidade de contribuições diferenciadas, e tem buscado criar produtos novos a partir da recombinação dos conhecimentos.

Buscando sintetizar os resultados encontrados, a fim de tornar o caso da indústria de semicondutores brasileira comparável a outras indústrias, percebe-se que é possível destacar que o modelo de colaboração adotado na indústria nacional de semicondutores pode ser caracterizado, de acordo com a amostra de respondentes, por uma quantidade crescente de projetos colaborativos temporários, laços compartilhados com universidades, outras DHs, pelo governo, pelas agências de fomento, por clientes, intermediários de inovação, fornecedores e incubadoras.

\section{QUADRO 5}

PRINCIPAIS CONTRIBUIÇÖES APONTADAS

NO ESTABELECIMENTO DE PRÁTICAS COLABORATIVAS

POR TIPO DE PARCEIRO

\begin{tabular}{|c|c|c|c|c|c|}
\hline \multicolumn{6}{|c|}{ PRÁTICAS COLABORATIVAS } \\
\hline $\begin{array}{l}\text { PRINCIPAIS } \\
\text { PARCEIROS } \\
\text { APONTADOS }\end{array}$ & $\begin{array}{l}\text { COLABORAÇÃO EM } \\
\text { P\&D - PARCERIA }\end{array}$ & $\begin{array}{l}\text { COLABORAÇÃO } \\
\text { EM ASPECTOS } \\
\text { GERENCIAIS }\end{array}$ & $\begin{array}{l}\text { COCRIAÇÃO } \\
\text { COM CLIENTES E } \\
\text { CONSULTORIA }\end{array}$ & $\begin{array}{l}\text { FINANCIAMENTO } \\
\text { DE P\&D }\end{array}$ & $\begin{array}{l}\text { AQUISIÇÃO DE } \\
\text { TECNOLOGIA }\end{array}$ \\
\hline $\mathrm{DH}$ & $\begin{array}{l}\text { Complementaridade } \\
\text { de recursos; } \\
\text { aprendizagem; } \\
\text { redução de } \\
\text { tempo e riscos } \\
\text { associados a projeto; } \\
\text { transferência de } \\
\text { conhecimentos. }\end{array}$ & $\begin{array}{l}\text { Troca de } \\
\text { informações } \\
\text { técnicas, } \\
\text { gerenciais } \\
\text { de mercado } \\
\text { e políticas } \\
\text { setoriais. }\end{array}$ & $\begin{array}{l}\text { Complementaridade } \\
\text { de recursos } \\
\text { (normalmente } \\
\text { quando não } \\
\text { domina uma etapa } \\
\text { ou um processo e } \\
\text { subcontrata outra } \\
\text { DH); transferência } \\
\text { de conhecimentos. }\end{array}$ & & \\
\hline
\end{tabular}


Quadro 5 (CONTINUAÇ̃̃o)

PRINCIPAIS CONTRIBUIÇÕES APONTADAS

NO ESTABELECIMENTO DE PRÁTICAS COLABORATIVAS

POR TIPO DE PARCEIRO

\begin{tabular}{|c|c|c|c|c|c|}
\hline \multicolumn{6}{|c|}{ PRÁTICAS COLABORATIVAS } \\
\hline $\begin{array}{l}\text { PRINCIPAIS } \\
\text { PARCEIROS } \\
\text { APONTADOS }\end{array}$ & $\begin{array}{l}\text { COLABORAÇÃO EM } \\
\text { P\&D - PARCERIA }\end{array}$ & $\begin{array}{l}\text { COLABORAÇÃO } \\
\text { EM ASPECTOS } \\
\text { GERENCIAIS }\end{array}$ & $\begin{array}{l}\text { COCRIAÇÃO } \\
\text { COM CLIENTES E } \\
\text { CONSULTORIA }\end{array}$ & $\begin{array}{l}\text { FINANCIAMENTO } \\
\text { DE P\&D }\end{array}$ & $\begin{array}{l}\text { AQUISIÇÃO DE } \\
\text { TECNOLOGIA }\end{array}$ \\
\hline Governo & & & & $\begin{array}{l}\text { Aporte de } \\
\text { recursos } \\
\text { financeiros. }\end{array}$ & \\
\hline $\begin{array}{l}\text { Agência } \\
\text { de fomento } \\
\text { à pesquisa } \\
\text { científica }\end{array}$ & & $\begin{array}{l}\text { Apoio } \\
\text { logístico } \\
\text { e suporte } \\
\text { comercial. }\end{array}$ & & $\begin{array}{l}\text { Aporte de } \\
\text { recursos } \\
\text { financeiros. }\end{array}$ & \\
\hline Universidade & $\begin{array}{l}\text { Infraestrutura; } \\
\text { apoio em P\&D; } \\
\text { complementaridade } \\
\text { de recursos; } \\
\text { transferência de } \\
\text { conhecimentos; } \\
\text { treinamento da } \\
\text { equipe. }\end{array}$ & & & & \\
\hline Cliente & & & $\begin{array}{l}\text { Ideia-concepção- } \\
\text { teste; } \\
\text { transferência } \\
\text { de know-how } \\
\text { tecnológico, } \\
\text { metodologias e } \\
\text { normas. }\end{array}$ & & \\
\hline Intermediário & Capta clientes. & & & & \\
\hline Fornecedor & $\begin{array}{l}\text { Parceria no } \\
\text { desenvolvimento } \\
\text { de IPs. }\end{array}$ & $\begin{array}{l}\text { Suplychain } \\
\text { - concentra } \\
\text { etapas do } \\
\text { processo } \\
\text { produtivo. }\end{array}$ & $\begin{array}{l}\text { Fornece ideias } \\
\text { de melhoria no } \\
\text { produto e também } \\
\text { no serviço ao } \\
\text { cliente. }\end{array}$ & & $\begin{array}{l}\text { Licenciamento } \\
\text { de IPs. }\end{array}$ \\
\hline
\end{tabular}

(continua) 
QUADRO 5 (CONCLUSÃO)

PRINCIPAIS CONTRIBUIÇÖES APONTADAS

NO ESTABELECIMENTO DE PRÁTICAS COLABORATIVAS

POR TIPO DE PARCEIRO

\begin{tabular}{|c|c|c|c|c|c|}
\hline \multicolumn{6}{|c|}{ PRÁTICAS COLABORATIVAS } \\
\hline $\begin{array}{l}\text { PRINCIPAIS } \\
\text { PARCEIROS } \\
\text { APONTADOS }\end{array}$ & $\begin{array}{l}\text { COLABORAÇÃO EM } \\
\text { P\&D - PARCERIA }\end{array}$ & $\begin{array}{l}\text { COLABORAÇÃO } \\
\text { EM ASPECTOS } \\
\text { GERENCIAIS }\end{array}$ & $\begin{array}{l}\text { COCRIAÇÃO } \\
\text { COM CLIENTES E } \\
\text { CONSULTORIA }\end{array}$ & $\begin{array}{l}\text { FINANCIAMENTO } \\
\text { DE P\&D }\end{array}$ & $\begin{array}{l}\text { AQUISIÇÃO DE } \\
\text { TECNOLOGIA }\end{array}$ \\
\hline Incubadora & Infraestrutura & $\begin{array}{l}\text { Apoio } \\
\text { administrativo, } \\
\text { gerencial, } \\
\text { jurídico e de } \\
\text { marketing. }\end{array}$ & & & \\
\hline
\end{tabular}

IPs = intelectual properties

Fonte: Elaborado pelos autores.

O conhecimento, na indústria brasileira de semicondutores, é criado por vínculos amplos e fluidos entre os atores participantes. Destaca-se também que as relações interorganizacionais das DHs brasileiras perpassam as fronteiras nacionais da indústria, mantendo acordos de colaboração com fornecedores, encapsuladoras e demais empresas das etapas de back-end, bem como com universidades que estão localizadas em países como Alemanha, Estados Unidos e Bélgica. Característica similar sobre a desvinculação regional foi apontada por Ahmadjian (2008) ao tratar das características das redes de criação do conhecimento da biotecnologia.

Ahmadjian (2008) sinaliza que, no Vale do Silício, os engenheiros, os administradores e os capitalistas de risco desenvolveram essa cultura compartilhada por meio de suas interações repetidas e de sua educação compartilhada em muitos casos, destacando seus antecedentes em Stanford. No Brasil, as interações repetidas ainda não são características das práticas de colaboração, haja vista que a revitalização da indústria começou a menos de dez anos (Bortolaso et al., 2013; Faccin, Bortolaso, \& Balestrin, 20I3) e parece não ter tido tempo suficiente para práticas recorrentes de colaboração. No entanto, verifica-se um movimento similar com relação à cultura compartilhada no Brasil, visto que todas as empresas receberam bolsistas do programa CI Brasil, os quais receberam formação em um dos dois centros de treinamento existentes aqui. Essa formação unânime auxilia na formação de uma cultura compartilhada, assim como no Vale do Silício.

$\mathrm{Na}$ indústria de semicondutores, encontra-se um conjunto amplo de laços, redes amplas e fluidas, movendo-se e configurando-se rapidamente, o que per- 
mite afirmar que, de acordo com a necessidade de determinado conhecimento, a empresa estabelece diferentes relacionamentos. A articulação desses atores acaba gerando um efeito sinérgico fundamental ao progresso técnico, na medida em que provoca uma síntese positiva das forças produtivas necessárias à inovação tecnológica.

Sabe-se que, embora o governo tenha sido apontado como parceiro nos projetos colaborativos, principalmente pelo financiamento em $\mathrm{P} \& \mathrm{D}$, ele é, ao mesmo tempo, o responsável pela organização de outras linhas de financiamento necessárias a uma empresa via bancos comerciais - que não são citados como parceiros diretos, mas coexistem no ecossistema.

\section{CONSIDERAÇÕES FINAIS}

Na nascente indústria de semicondutores nacional, há uma diversidade de interações entre fornecedores, clientes, universidades e agências de fomento, e, inclusive, com concorrentes estrangeiros. De acordo com os resultados do estudo, parece possível enfatizar que, na indústria brasileira, existe um conjunto amplo de laços não familiares e bastante fluidos que se movem e se configuram rapidamente. Cabe também ressaltar que o governo tem um papel importante na influência da inovação, baseando-se no princípio da interdependência, haja vista a criação de mecanismos dinâmicos e o fomento por parte de políticas públicas e ações governamentais. Refere-se principalmente àquelas ações para incentivo da inovação e interação entre os atores, formação e capacitação de pessoas, exploração do comércio internacional, incentivo à captação de recursos, redução da carga tributária etc.

Entre as principais formas de colaboração empregadas, estão a colaboração em $P \& D$ e aspectos gerenciais, cocriação a montante e a jusante na cadeia produtiva, financiamento de $P \& D$ e aquisição de tecnologia. A partir da evidenciação dos atores e das práticas colaborativas, foi possível criar uma matriz correlacionando-os, fazendo emergir da análise uma quantidade expressiva de contribuições advindas da relação colaborativa por tipo de parceiro.

Além de um mapeamento das relações colaborativas encontradas na indústria de semicondutores, que do ponto de vista prático auxilia na tomada de decisão dos empresários e também dos formuladores de políticas públicas, este estudo se destaca pela importante contribuição teórica. Os resultados da pesquisa devem contribuir para o limitado conjunto de obras que se dedicam, na literatura interorganizacional, à abordagem processual que traz aportes teóricos e novos conhecimentos sobre o que acontece no interior dos projetos colaborativos e que garantem o seu sucesso. 
A análise da indústria brasileira de semicondutores requer mais estudos e debates. Uma das limitações deste estudo está vinculada à forma de coleta de dados, que não permitiu a análise individual de cada projeto, de acordo com a sua natureza e rede de atores, nem mesmo uma avaliação mais criteriosa sobre a opinião dos participantes. Nesse sentido, estudos futuros poderão investigar quais são os tipos de interação - modelos de projetos - capazes de afetar a capacidade produtiva e inovativa do setor, podendo ainda mapear a intensidade da inovação, conforme o nível de interação. Ainda, poderão proporcionar um esquema teórico-conceitual sobre os processos de inovação no setor, visando captar a essência da evolução do ecossistema: a inovação interativo-colaborativa.

\section{R\&D COLLABORATIVE PRACTICES: A CASE STUDY IN THE BRAZILIAN SEMICONDUCTOR INDUSTRY}

\section{ABSTRACT}

Recent studies point to the need of opening the R\&D model for greater interaction, complementarity and cooperation with external actors. Thus, the environment of the company becomes an ecosystem of organic relationships among the various sources of knowledge that interact dynamically building up applied knowledge in the R\&D process. The question that arises for this research is: which are the collaborative $R \& D$ practices and how do they occur in an industry with high technological complexity? In order tomake the research clearer, we aimed to investigate collaborative R\&D projects within the Brazilian semiconductor industry. This paper investigates the structure of collaborative R\&D projects in the semiconductor industry in Brazil, as well as unveils the most common collaborative practices among actors. For the field study, 2I projects in R\&D, developed by Brazilian Design Houses from 2008 to 2013, were investigated. The study is a contextual approach to Brazilian projects, identifying the main actors, their most significant contributions, and forms of collaboration with their partners. The results show a series of collaborative practices in $R \& D$ projects. In the growing industry of national semiconductor, there is a diversity of interactions among suppliers, customers, universities and funding agencies, including foreign competitors. According to the study results, it seems possible to emphasize that in the Brazilian industry there is a broad set of fluid ties that move and shape quickly. It is also noteworthy that the government plays an important role in influencing innovation, based on the principle of interdependence, given the creation of dynamic mechanisms and by fostering public 
policies and governmental actions; especially those actions to stimulate innovation and interaction among actors, training and capacity building, development of international trade, encouraging fundraising, tax reduction, etc. Among the main collaborative practices, we find collaboration in $R \& D$ and managerial aspects, upstream co-creation and downstream in the supply chain, $R \& D$ raising funds, and technology acquisition.

\section{KEYWORDS}

Collaborative practices. Collaborative projects. R\&D. Collaboration. Semiconductors.

\section{PRÁCTICAS DE COLABORACIÓN EN P\&D: ESTUDIO EN LA INDUSTRIA BRASILEÑA DE SEMICONDUCTORES}

\section{RESUMEN}

Estudios recientes demuestran la necesidad de apertura del modelo de P\&D para una mayor interacción, complementariedad y cooperación con actores externos. Así, el ambiente de la empresa se convierte en un ecosistema de relaciones orgánicas entre las diversas fuentes de conocimientos que interactúan de forma dinámica, creando el conocimiento aplicado al proceso de P\&D. Este artículo tiene por finalidad investigar la estructura de los proyectos de colaboración de P\&D en la industria de semiconductores conducidos en Brasil, además de desvelar las prácticas de colaboración más comunes entre los actores. Por lo tanto, la cuestión que se presenta para esta investigación es: ¿cuáles y cómo ocurren las prácticas de colaboración de $\mathrm{P} \& \mathrm{D}$ en una industria de alta complejidad tecnológica? Para lanzar luz a la presente investigación, se analizaron proyectos de colaboración de P\&D junto a la industria brasileña de semiconductores. Para el estudio de campo, fueron investigados 2I proyectos de P\&D, desarrollados por Design Houses brasileñas de 2008 a 20I3. El estudio hace un abordaje contextual de los proyectos brasileños, identificando quiénes son los principales actores, cuáles son sus contribuciones más relevantes y las formas de colaboración con sus socios. Los resultados demuestran una serie de prácticas de colaboración en los proyectos de P\&D. En la naciente industria de semiconductores nacional, existe una diversidad de interacciones entre proveedores, clientes, universidades y agencias de fomento, e, incluso, con competidores extranjeros. Según los resul- 
tados del estudio, parece posible enfatizar que, en la industria brasileña, existe un conjunto amplio de lazos no familiares y bastante fluidos, que se mueven y se configuran rápidamente. Se debe también resaltar que el gobierno tiene un papel importante en la influencia de la innovación, basándose en el principio de la interdependencia, siendo ejemplos la creación de mecanismos dinámicos y el fomento por parte de políticas públicas y acciones gubernamentales, principalmente aquellas acciones para incentivo de la innovación e interacción entre los actores, formación y capacitación de personas, explotación del comercio internacional, incentivo a la captación de recursos, reducción de la carga tributaria, etc. Entre las principales formas de colaboración empleadas están la colaboración en P\&D y aspectos gerenciales, co-creación ascendente y descendente en la cadena productiva, financiación de P\&D y adquisición de tecnología.

\section{PALABRAS Clave}

Prácticas de colaboración. Proyectos de colaboración. P\&D. Colaboración. Semiconductores.

\section{REFERÊNCIAS}

Aaker, D. A., Kumar, V., \& Day, G. S. (200I). Marketing research (7th ed.). New York: John Wiley $\&$ Sons, Inc.

Agência Brasileira de Desenvolvimento Industrial (20II). As design houses (DHs) brasileiras (Relatório analítico). Brasília, DF: Abid.

Ahmadjian, C. (2008). Criação do conhecimento interorganizacional: conhecimento e redes. In H. Takeuchi \& I. Nonaka. Gestão do conhecimento. Porto Alegre: Bookman.

Ahola, T. (2009). Efficiency in project networks: the role of inter-organizational relationships in project implementation. Doctoral dissertation, Helsinky University of Technology, Espoo, Finland.

Aronson, Z. H., Lechler, T., Reily, R. R., \& Shenhar, A. J. (200I). Project spirit. A strategic concept. PICMET'01 - Portland International Conference on the Management of Engineering and Technology, Portland, OR, USA, I.

Axelrod, R. (20Io). A evolução da cooperação. São Paulo: Leopardo.

Axelsson, R., \& Axelsson, S. B. (2006). Integration and collaboration in public health - a conceptual framework. The International Journal of Health Planning and Management, 21(I), 75-88.

Balestrin, A., \& Verschoore, J. R. S. (2008). Redes de cooperação empresarial: estratégias de gestão na nova economia. Porto Alegre: Bookman.

Barajas, A., Huergo, E., \& Moreno, L. (2012). Measuring the impact of international R\&D cooperation: the case of Spanish firms participating in the EU Framework Programme. Recuperado em I5 janeiro, 2013, de http://www.ecap.uab.es/secretaria/seminaris/BarajasHuergoMoreno.pdf. 
Bengtsson, M., \& Kock, S. (I999). Cooperation and competition in relationships between competitors in business networks. Journal of Business \& Industrial Marketing, 14(3), I78-I94.

Bortolaso, I. V., Teixeira, R., Balestrin, A., \& Faccin, K. (2013). The trajectory of Brazilian semiconductor industry: an economic, governmental, and technological perspectives. Porto Alegre: Iamot.

Bourreau, M., \& Dogan, P. (20I0). Cooperation in product development and process R\&D between competitors. International Journal of Industrial Organization, 28(2), I76-I90.

Breschi, S., \& Malerba, F. (I997). Sextoral innovation systems: technologial regimes, Schumpeterian dynamics, and spatial boundaries. In C. Edquist (Ed.). Systems of innovation - technologies, institutions and organizations (pp. I30-156). London, Washington: Pinter.

Brostrom, A. (20I2). Firms' rationales for interaction with research universities and the principles for public co-funding. The Journal of Technology Transfer, 37, 313-329.

Brown, C., \& Linden, G. (2011). Chips and change: how crisis reshapes the semiconductor industry. Cambridge: MIT Press.

Calamel, L., Defélix, C., Picq, T., \& Retour, D. (20I2). Inter-organisational projects in French innovation clusters: the construction of collaboration. International Journal of Project Management, 30(I), 48-59.

Cassiman, B., Di Guardo, M. C., \& Valentini, G. (2009). Organising R\&D projects to profit from innovation: insights from co-opetition. Long Range Planning, 42(2), 216-233.

Chandler, A. D., Jr. (2002). O século eletrônico. Rio de Janeiro: Campus.

Chesbrough, H. W. (2003). Open innovation: the new imperative for creating and profiting from technology. Boston: Harvard Business School Press.

Chiarioni, D., Chiesa, V., \& Frattini, F. (2010). Unravelling the process from closed to open innovation: evidence from mature, asset-intensive industries. R\&D Management, 4O(3), 222-245.

Cohen, W., \& Levinthal, D. (Orgs.) (I990). Absorptive capacity: a new perspective on learning and innovation. Administrative Science Quarterly, 35, I28-152.

Cropper, S., Ebers, M., \& Huxham, C. (Orgs.). (2008). The Oxford Handbook of interorganizational relations. Oxford: Oxford University Press.

Davis, J. P., \& Eisenhardt, K. M. (20II). Rotating leadership and collaborative innovation: recombination processes in symbiotic relationships. Administrative Science Quarterly, 56 (2), I59-20I.

Deck, C., \& Erkal, N. (2013). An experimental analysis of dynamic incentives to share knowledge. Economic Inquiry, 51(2), I622-1639.

Defélix, C., Colle, R., \& Rapiau, M. T. (2008). Prendre en compte le facteur humain au sein des pôles de compétitivité: la longue marche vers l'innovation sociale. Revue Management e Avenu, 6, 9-Io. Deng, P. (2008). Applying a market-based approach to the development of a sharing-enabled KM model for knowledge-intensive small firms. Information Systems Management, 25(2), I74-187.

Dietrich, P., Eskerod, P., Dalcher, D., \& Sandhawalia, B. (2010). The dynamics of collaboration in multipartner projects. Project Management Journal, 41(4), 59-78.

Dittrich, L., \& Duysters, G. (2007). Networking as a means to strategy change: the case of open innovation in mobile telephony. The Journal os Product Innovation Management, 24(6), 5I0-52I.

Dyer, J. H., \& Singh, H. (I998). The relational view: cooperative strategy and sources of interorganizational. Academy of Management Review, 23(4), 660-679.

Eloranta, K. (2007). Supplier relationship management in networked project business. Licentiate's thesis, Helsinki University of Technology, Helsinki. 
Faccin, K., Bortolaso, I., \& Balestrin, A. (20I3). Política de desenvolvimento da indústria brasileira de semicondutores: a visão relacional do programa CI-Brasil. Anais do Encontro Nacional de Pós-Graduação em Administração, Rio de Janeiro, RJ, Brasil, 37.

Furman, J. L., \& McGarvie, M. (2009). Academic collaboration and organizational innovation: the development of research capabilities in the US pharmaceutical industry, I927-I946. Industrial and Corporate Change, 18(5), 929-961.

Gallego, J., Rubalcaba, L., \& Suárez, C. (2013). Knowledge for innovation in Europe: the role of external knowledge on firms cooperation strategies. Journal of Business Research, 66, 2034-204I.

Gassmann, O., Enkel, E., \& Chesbrough, H. W. (2010). The future of open innovation. R\&D Management, 4O(3), 2I3-22I.

Goodman, R. A., \& Goodman, L. P. (1976). Some management issues in temporary systems: a study of professional development and manpower - the theater case. Administrative Science Quarterly, 21(3), 494-501.

Granovetter, M. S. (I973). The strength of weak ties. The American Journal of Sociology, 78(6), I360-I380.

Gutierrez, R., \& Leal, C. (2004). Estratégias para uma indústria de circuitos integrados no brasil. Recuperado em I6 dezembro, 20I2, de http://www.bndes.gov.br/conhecimento/publi.pdf.

Hagedoorn, J., \& Wang, N. (20I2). Is there complementarity or substitutability between internal and external R\&D strategies? Research Policy, 41, I072-1083.

Han, K., Oh, W., Im, K. S., Hang, R. M., Oh, H., \& Pinsonneault, A. (20I2). Value cocreation and wealth spillover in open innovation allances. MIS Quarterly, 36(I), 29I-3I5.

Hoang, H., \& Rothaermel, F. T. (20I0). leveraging internal and external experience: exploration, exploitation, and R\&D project performance. Strategic Management Journal, 31, 734-758.

Howells, J. (2006). Intermediation and the role of intermediaries in innovation. Research Policy, 35, 715-728.

Hughes, B., \& Wareham, J. (2010). Knowledge arbitrage in global pharma: a synthetic view of absorptive capacity and open innovation. R\&D Management, 4O(3).

Jones, C., \& Lichtenstein, B. B. (2008). Temporary inter-organizational projects: how temporal and social embeddedness enhance coordination and manage uncertainty. In S. Cropper, M. Ebers \& C. Huxham (Orgs.). The Oxford Handbook of interorganizational relations (pp. 340-358). Oxford: Oxford University Press.

Johnson, W. H. A. (2008). Roles, resources and benefits of intermediate organizations supporting triple helix collaborative R\&D: The case of Precarn. Technovation, 28(8), 495-505.

Kapoor, R., \& McGrath, J. P. (20I4).Un masking the inter play between technology evolution and R\&D collaboration: evidence from the global semiconductor manufacturing industry, I990-2010. Research Policy, 43, 555-569.

Kline, S. J., \& Rosenberg, N. (I986). An overview of innovation. In R. Landau \& N. Rosenberg (Eds.). The positive sum strategy: harnessing technology for economic. Washington, DC: Growth National Academy Press.

Kohtamäki, M., Partanen, J., \& Möller, K. (20I3). Making a profit with R\&D services: the critical role of relational capital. Industrial Marketing Management, 42, 7I-8I.

Levitas, E. M., \& McFadyen, A. (2009). Managing liquidity in research-intensive firms: signaling and cash flow effects of patents and alliance activities. Strategic Management Journal, 30, 659-678. 
Lindkvist, L. (2005). Knowledge communities and knowledge collectivities: a typology of knowledge work in groups. Journal of Management Studies, 42(6), II89-I2IO.

Malerba, F. (2002). Sectoral system of innovation and production. ResearchPolicy, 31, 247-264.

Marín, P., \& Siotis, L. G. (2008). Public policies towards reserach joint venture: institutional design and participants characteristics. Research Policy, 37(6-7), I057-1065.

Martins, G. A. (2008). Estudo de caso: uma reflexão sobre a aplicabilidade em pesquisas no Brasil. Revista de Contabilidade e Organizações, 2(2), 8-I8.

Meredith, J. (1998). Building operations management theory through case and field research. Journal of Operations Management, 16, 44I-454.

Minayo, M. C. D. S. (I994). Pesquisa social. Teoria, Método e Criatividade, 17.

Ministério da Ciência, Tecnologia e Inovação (20II). CI Brasil: caderno informativo. Brasília: Ministério da Ciência e Tecnologia.

Mizruchi, M. S. (I993). Cohesion, equivalence, and similarity of behavior: a theoretical and empirical assessment. Social Networks, 15, 275-307.

Morandi, V. (2013). The management of industry-university joint research projects: how do partners coordinate and control R\&D activities? The Journal of Technology Transfer, 38, 69-92.

Mowery, D. C. (2OII). Learning from one another? International policy "emulation" and universityindustry technology transfer. Industrial and Corporate Change, 20(6), I827-I853.

Nelson, R., \& Winter, S. (I982). An evolutionary theory of economic change. Cambridge: Harvard University Press.

Nonaka, I., Toyama, R., \& Hirata, T. (20II). Teoria e casos de empresas baseadas no conhecimento: managing flow. Porto Alegre: Bookman.

Noteboom, B. (2008). Learning and innovation in inter-organizational. inter-organizational relationships, chains and networks: a supply perspective. In S. Cropper, M. Ebers \& C. Huxham (Orgs.). The Oxford Handbook of interorganizational relations. Oxford: Oxford University Press.

Okamuro, H. (2OII). R\&D productivity and the organization of cluster policy: an empirical evaluation of the Industrial Cluster Project in Japan. The Journal of Technology Transfer, 36(2), II7-I44.

Paier, M., \& Scherngell, T. (2OII). Determinants of collaboration in European R\&D networks: empirical evidence from a discrete choice model. Industry and Innovation, 18(I), 89-I04.

Pittaway, L., Robertson, M., Munir, K., Denyer, D., \& Neely A. (20I4). Networking and innovation: a systematic review of the evidence. International Journal of Management Reviews, 5-6(3-4), I37-I68. Prahalad, C. K., \& Ramaswamy, V. (2000). Co-opting customer competence. Harvard Business Review, 78(I), 79-90.

Roijakkers, N., \& Hagedoorn, J. (2006). Inter-firm R\&D partnering in pharmaceutical biotechnology since I975: trends, patterns, and networks. Research Policy, 35, 43I-446.

Rothwell, R. (I995). Industrial innovation: success, strategy, trends. In M. Dodgson \& R. Rothwell. The handbook of industrial innovation. Cheltenham: Edward Elgar.

Rutten, R., \& Oerlemans, L. (2009). Temporary inter-organizational collaboration as a driver of regional innovation: an evaluation. International Journal of Innovation and Regional Development, 1(3), 2II-34.

Santamaría, L., Barge-Gil, A., \& Modrego, A. (2010). Public selection and financing of R\&D cooperative projects: credit versus subsidy funding. Research Policy, 39(4), 549-563. 
Semiconductor Industry Association. Global semiconductor sales flat month - on - month. 2010. Recuperado em I3 julho, 20I2, de http://www.sia-online.org/news/2010/ı2/03/global-sales-reports-201о/global-semiconductor-sales-flat-month-on-month.

Shih, W., Pisano, G., \& King, A. A. (2008, maio). Radical collaboration: IBM microelectronics joint development alliances. Harvard Business School Case, 608-ı2.

Siggelkow, N. (2007). Persuasion with case studies. Academy of Management Journal, 50, 20-24.

Teixeira, E. B. (2003). Análise de dados na pesquisa científica: importância e desafios em estudos organizacionais. Desenvolvimento em Questão, 1(2), I77-20I.

Thorgren, S., Wincent, J., \& Örtqvist, D. (20I2). Designing interorganizational networks for innovation: an empirical examination of network configuration, formation and governance. Journal of Engineering and Technology Management, 26(3), I48-166.

Tzabbar, D., Aharonson, B. S., \& Amburgey, T. L. (2013). When does tapping external sources of knowledge result in knowledge integration? Research Policy, 42, 48I-494.

Un, C. A., Cuervo-Cazurra, A., \& Asakawa, K. (2010). R\&D collaborations and product innovation. Journal of Product Innovation Management, 27(5), 673-689.

Yin, R. K. (I994). Case study research: design and methods. California: Sage.

Zanzouri, C., \& Francois, J. C. (2013). Knowledge management practices within a collaborative R\&D project: case study of a firm in a cluster of railway industry. Business Process Management Journal, 19(5), 819-840. 